\title{
Deformation microstructures, strengthening mechanisms, and electrical conductivity in a $\mathrm{Cu}-\mathrm{Cr}-\mathrm{Zr}$ alloy
}

\author{
R. Mishnev*, I. Shakhova, A. Belyakov, R. Kaibyshev \\ Belgorod State University, Pobeda 85, Belgorod 308015, Russia
}

\section{A R T I C L E I N F O}

\section{Article history:}

Received 27 November 2014

Received in revised form

22 January 2015

Accepted 23 January 2015

Available online 11 February 2015

Keywords:

EBSD

Non-ferrous alloys

Equal channel angular processing

Grain refinement

Mechanical characterization

Hardening

\begin{abstract}
A B S T R A C T
The ultrafine-grained microstructures, mechanical properties and electrical conductivity of a $\mathrm{Cu}-0.87 \%$ $\mathrm{Cr}-0.06 \% \mathrm{Zr}$ alloy subjected to multiple equal channel angular pressing (ECAP) at temperatures of 473$673 \mathrm{~K}$ were investigated. The new ultrafine grains resulted from progressive increase in the misorientations of strain-induced low-angle boundaries during the multiple ECAP process. The development of ultrafine-grained microstructures is considered as a type of continuous dynamic recrystallization. The multiple ECAP process resulted in substantial strengthening of the alloy. The yield strength increased from $215 \mathrm{MPa}$ in the original peak aged condition to $480 \mathrm{MPa}$ and $535 \mathrm{MPa}$ after eight ECAP passes at $673 \mathrm{~K}$ and $473 \mathrm{~K}$, respectively. The strengthening was attributed to the grain refinement and high dislocation densities evolved by large strain deformation. Modified Hall-Petch analysis indicated that the contribution of dislocation strengthening to the overall increment of yield stress (YS) through ECAP was higher than that of grain size strengthening. The formation of ultrafine grains containing high dislocation density leads to a small reduction in electrical conductivity from 80 to $70 \%$ IACS.
\end{abstract}

(c) 2015 Elsevier B.V. All rights reserved.

\section{Introduction}

$\mathrm{Cu}-\mathrm{Cr}-\mathrm{Zr}$ alloys are used in critical functional and structural applications that frequently require both a high mechanical strength and a high electrical conductivity [1-4]. However, these properties typically have opposing characteristics, e.g., copper alloys may be strong or exhibit high electrical conductivity, but they are rarely both [5]. Attractive combination of ultimate tensile strength (UTS) above $530 \mathrm{MPa}$ and electrical conductivity above 80\% IACS (International Annealed Copper Standard defines 17.241 $\mathrm{n} \Omega \mathrm{m}$ as $100 \%$ ) makes the $\mathrm{Cu}-\mathrm{Cr}-\mathrm{Zr}$ alloys interesting for contact wire for high speed railways [1]. These alloys are age-hardenable materials $[1,2,5,6]$. The heat treatment of these alloys provides a UTS of approximately $400 \mathrm{MPa}$, which is equal or even less than that of hard-drawn copper wire $[2,5,7,8]$. Moreover, a $\mathrm{Cu}-\mathrm{Cr}-\mathrm{Zr}$ alloy in peak aged condition exhibits a lower IACS value than that of cold-drawn pure $\mathrm{Cu}$.

The properties of $\mathrm{Cu}-\mathrm{Cr}-\mathrm{Zr}$ alloys can be improved by means of an appropriate thermo-mechanical processing (TMP). The most promising processing methods, which allow us the fabrication of advanced $\mathrm{Cu}$ alloys with improved mechanical properties, involve severe plastic deformations [9-17]. It should be noted that the significant strengthening through intense plastic straining is not accompanied by a

\footnotetext{
* Corresponding author. Tel.: +7 4722 585457; fax: +7 4722585417.

E-mail address: mishnev@bsu.edu.ru (R. Mishnev).
}

remarkable degradation of electrical conductivity $[11-13,16,17]$. The most impressive strength results have been obtained using high pressure torsion $[13,16,17]$, although this specific technique is currently used only for laboratory simulations. In contrast, TMP based on equal channel angular pressing (ECAP) is capable of achieving a beneficial combination of mechanical properties and electro-conductivity in bulk $\mathrm{Cu}-\mathrm{Cr}-\mathrm{Zr}$ products $[1,7,18-21]$. Recently, ECAP combined with the Conform process providing production of long-length billets was developed [22-24]. This ECAP-Conform process following continuous wire casting can be easily adapted for use in industrial operations for fabrication of bulk billets with a sufficient length for the consequent drawing of contact wire with a standard length $\geq 1400 \mathrm{~m}$. However, the ECAP-Conform process has a critical disadvantage. To achieve UTS $\geq 530 \mathrm{MPa}$ in $\mathrm{Cu}-\mathrm{Cr}-\mathrm{Zr}$ alloys, four or more repetitive passes are required, and in each pass, the long-length billet is inserted into the rolling mill, rolled/pressed through the die, removed and then reinserted $[7,8,20,21]$. Therefore, the optimization of a TMP route providing a decreased number of the ECAP passes is very important for the implementation of the ECAP-Conform technique in commercial use.

The main aim of the present study is the examination of the effect of deformation structure produced by ECAP at temperatures ranging from 473 to $673 \mathrm{~K}$ on the mechanical properties and electrical conductivity in a $\mathrm{Cu}-\mathrm{Cr}-\mathrm{Zr}$ alloy. It was shown [20] that there is no remarkable difference between the effect of discontinuous ECAP and continuous ECAP-Conform on the microstructure and mechanical properties. Therefore, ECAP can be used as an effective processing tool for research works simulating industrial ECAP-Conform processing. The 
second aim of the present study is to quantify the dominant strengthening mechanisms in this alloy. This information is necessary for the development of an optimal route of TMP providing an attractive combination of strength and electric conductivity. For this purpose, the relationships between different types of deformation structures and properties in a $\mathrm{Cu}-\mathrm{Cr}-\mathrm{Zr}$ alloy are considered in detail.

It is generally accepted that the improvement of mechanical properties of the metals and alloys subjected to ECAP is achieved by the development of ultrafine-grained structures [24]. However, the grain size strengthening in accordance with the Hall-Petch relationship [25]:

$\sigma_{0.2}=\sigma_{0}+K_{\mathrm{H}} d^{-0.5}$

where $\sigma_{0.2}$ is the offset yield stress (YS), $d$ is the effective grain size, $\sigma_{0}$ is the friction stress, and $K_{\mathrm{H}}$ is the Hall-Petch coefficient, is of low efficiency in copper and $\mathrm{Cu}-\mathrm{Cr}-\mathrm{Zr}$ alloys because of the small values of $K_{\mathrm{H}} \sim 0.11$ and $\sim 0.139 \mathrm{MPa} \mathrm{m}^{0.5}$, respectively [8,26]. Substitutional solutes strongly affect these values, which can be as high as $\sim 0.45 \mathrm{MPa} \mathrm{m}^{0.5}$ in $\mathrm{Cu}-6 \mathrm{wt} \% \mathrm{Al}$ [26]. However, electron scattering on solutes leads to a dramatic decrease in electro-conductivity [27]. Therefore, a copper alloy with IACS $\geq 80 \%$ must have a pure copper matrix with a negligible amount of solutes as $\mathrm{Cu}-\mathrm{Cr}-\mathrm{Zr}$ alloys $[3,5]$. In addition to the grain size strengthening, the dislocation strengthening caused by high dislocation density [28-33] may contribute significantly to the overall increase in the YS $[3,8,18]$. The dispersion strengthening associated with nanoscale $\mathrm{Cr}$ or Heusler phase $\left(\mathrm{CrCu}_{2} \mathrm{Zr}\right)$ particles [5] may also contribute to the overall YS. A usage of appropriate aging treatment can provide an additional strength increment of about 10-20\% [12]. The nanoscale precipitates dispersed in ultrafine-grains significantly enhance strain hardening, resulting in simultaneous improvement of strength and plasticity of $\mathrm{Cu}-\mathrm{Cr}-\mathrm{Zr}$ alloys [11]. However, limited statistics of the dislocation density and the distribution of secondary phase particles are available [8]. As a result, the structure-property relationships in $\mathrm{Cu}$ and its alloys subjected to intense plastic straining remain unclear.

The grain refinement in $\mathrm{Cu}$ and its alloys during ECAP occurs through continuous dynamic recrystallization (cDRX) due to gradual transformation of strain-induced low-angle boundaries (LAB) into high-angle boundaries (HAB) [5,28-30,33]. As a result, distinctly different deformation structures evolve after different strains $[5,28-$ 30,33]. Initially appearing is a high density of dislocations, which are partially organized in extended planar low-angle boundaries, also defined as geometrically necessary boundaries (GNBs) [5,28-30,34]. The dislocation density stored in LABs may contribute significantly to both the grain size strengthening and the dislocation strengthening concurrently $[35,36]$. It was recently shown for cold working of $\mathrm{Al}$ $[36,37]$ that the exact characteristics of the deformation-induced

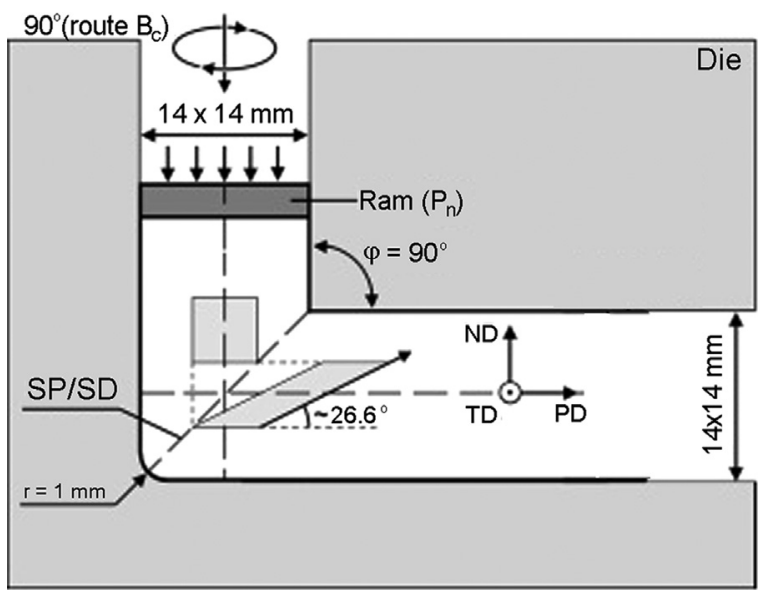

Fig. 1. Schematic illustration of the ECAP facility, showing the shearing plane (SP) or shear direction (SD) within the die and the adopted coordinate system. boundary assembly are not so important for mechanical properties. Similarly, the formation of strain-induced low- to high-angle boundaries may be sufficient for attaining high YS in $\mathrm{Cu}$ and its alloys. The highest YS was attained in pure $\mathrm{Cu}$ after the second ECAP pass, after which the strain-induced boundaries are mainly planar LABs $[28,36]$. Therefore, a high strength in $\mathrm{Cu}-\mathrm{Cr}-\mathrm{Zr}$ alloys could be attained in two or even one ECAP pass. Thus, the specific focus of the present study is the analysis of the role of planar LABs [37-42] in the strengthening of a $\mathrm{Cu}-\mathrm{Cr}-\mathrm{Zr}$ alloy.

\section{Experimental section}

An alloy of $\mathrm{Cu}-0.87 \mathrm{wt} \% \mathrm{Cr}-0.06 \mathrm{wt} \% \mathrm{Zr}$ was fabricated by direct chill casting. Next, the alloy was subjected to solution treatment at a temperature of $1193 \mathrm{~K}$ for $30 \mathrm{~min}$, water quenched, and then aged at a temperature of $723 \mathrm{~K}$ for $4 \mathrm{~h}$. The billets with starting dimensions of $14 \mathrm{~mm} \times 14 \mathrm{~mm} \times 80 \mathrm{~mm}$ were subjected to ECAP at temperatures of $473 \pm 5 \mathrm{~K}, 573 \pm 5 \mathrm{~K}$ and $673 \pm 5 \mathrm{~K}$ via route $\mathrm{B}_{\mathrm{C}}$ [24], at which each sample is rotated by $90^{\circ}$ around the pressing direction between each pass, for total strains of $\sim 1, \sim 2, \sim 4, \sim 8$ and $\sim 12$ using an isothermal die having a channel angle of $90^{\circ}$ with a square cross-section of $14 \times 14 \mathrm{~mm}^{2}$ (Fig. 1) and a pressing speed of $\sim 5 \mathrm{~mm} / \mathrm{s}$. The specimens for microstructural examination were cut from the central parts of the pressed rods in the longitudinal direction parallel to the last pressing direction, i.e., the TD plane (Fig. 1). The samples for transmission or scanning electron microscopy were electro-polished using an electrolyte of $\mathrm{HNO}_{3}: \mathrm{CH}_{3} \mathrm{OH}=1: 3$ at a temperature of $263 \mathrm{~K}$ with a voltage of 10 V. A Quanta 250 Nowa scanning electron microscope (SEM) equipped with an electron backscattering diffraction (EBSD) analyzer incorporating orientation imaging microscopy (OIM) was used for the structural characterizations. The high-angle boundaries (HABs) and low-angle boundaries (LABs) were defined when adjacent pixels in the map have a misorientation of $\geq 15^{\circ}$ and $2^{\circ} \leq \theta<15^{\circ}$ and depicted in misorientation maps using black and white lines, respectively. The terms "grain" and "subgrain" are used to define the crystallites, which are entirely delimited by the HABs and LABs, respectively $[41,42]$. "(Sub)grains" are crystallites that are bound partly by the LABs and partly by the HABs $[41,42]$. The EBSD scans were performed with a step size of $100 \mathrm{~nm}$ for the samples processed by 1 and 2 ECAP passes and $60 \mathrm{~nm}$ for the samples subjected to 4,8 and 12 ECAP passes. The OIM images were subjected to clean-up procedures, setting a minimal confidence index of 0.1. The mean grain size was measured using the linear intercept method, with orthogonal grids on the OIM images counting the distance between HABs. The fractions of ultrafine grains ( $F_{\mathrm{UFG}}$ ) with a size of $D \leq 2 \mu \mathrm{m}$ were obtained using OIM software (EDAX TSL, version 5.2). The dislocation structures and distribution of secondary phases were examined using a Jeol JEM2100 transmission electron microscope (TEM). The dislocation densities were estimated by counting the individual dislocations in the grain/subgrain interiors using a method described elsewhere [41]. The tensile tests were performed at ambient temperature using an Instron 5882 testing machine. The specimens with a gauge length of $6 \mathrm{~mm}$ and cross section of $1.5 \mathrm{~mm} \times 3 \mathrm{~mm}$ were tensioned at an initial strain rate of $2 \times 10^{-3} \mathrm{~s}^{-1}$ with the tensile axis parallel to the last ECAP axis.

\section{Results}

\subsection{Initial structure}

The initial samples were characterized by a uniform microstructure with an average grain size of $\sim 12 \mu \mathrm{m}$ (Fig. 2a) and a low 

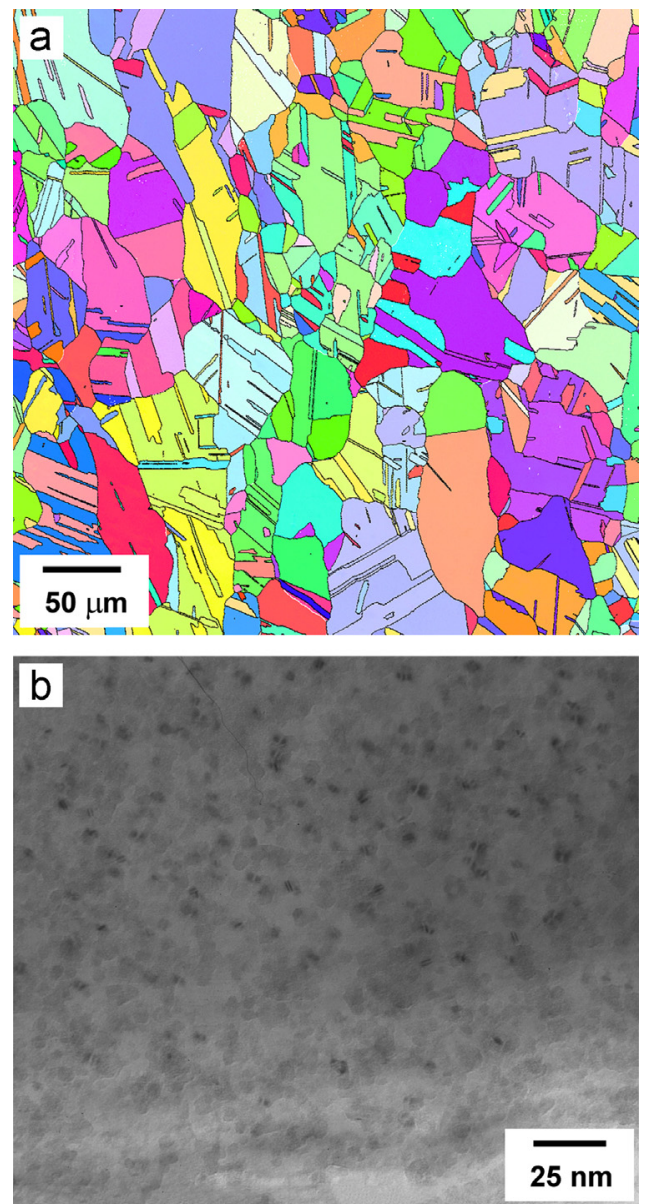

Fig. 2. Initial microstructure (a) and dispersed particles (b) in the $\mathrm{Cu}-\mathrm{Cr}-\mathrm{Zr}$ alloy after aging treatment. The white and black lines in (a) indicate the low-angle $\left(\theta<15^{\circ}\right)$ and high-angle $\left(\theta \geq 15^{\circ}\right)$ boundaries, respectively.

dislocation density of $\sim 10^{12} \mathrm{~m}^{-2}$. The initial microstructure consisted of a large fraction of HABs including approximately $50 \%$ of $\Sigma 3$ CSL boundaries corresponding to annealing twins. The fraction of LABs with misorientations less than $15^{\circ}$ did not exceed 0.03 . The aging treatment led to precipitation of high dense chromium particles with sizes of approximately $4 \mathrm{~nm}$, and their volume fraction was 0.103 pct. (Fig. 2b).

\subsection{Grain refinement during the multiple ECAP process}

Figs. 3-5 show typical deformation microstructures and misorientation distributions of the $\mathrm{Cu}-\mathrm{Cr}-\mathrm{Zr}$ alloy after 1, 2, 4, 8 and 12 ECAP passes; the resulting structural parameters are summarized in Figs. 6 and 7. At $\varepsilon \sim 1$, the elongation of original grains along the pressing direction occurs (Fig. 3a). In addition, the appearance of a large number of planar boundaries, which delimitate microbands, occurs (Figs. 3a and 4a). The majority of these planar boundaries have low-angle misorientations, as suggested by both a single-spot diffraction pattern in Fig. 4a and a large fraction of LABs on the misorientation distribution (Fig. 5). A small fraction of the extended boundaries exhibits high-angle misorientations (Figs. 3a and 5). The formation of these planar boundaries is indicative of the extensive localization of the dislocation glide, resulting in the formation of HABs after relatively low strain [42]. The boundaries of microshear bands are aligned with the $\{111\}$ planes with a very small inclination angle (Fig. 4a), but there is no evidence for their alignment along the die shear direction (SD in Fig. 3a) [43]. A lamellar-like substructure [28], with boundary spacing of $\sim 200 \mathrm{~nm}$ and a high dislocation density above $10^{14} \mathrm{~m}^{-2}$ (Fig. 4a and b), developed during the first ECAP pass. Thus, the first pass induces a high density of lattice dislocations, which partially arranged into dislocation boundaries with low-angle misorientations and are partially pinned by $\mathrm{Cr}$ particles in crystallite interiors. As a result, the number of boundaries on $1 \mathrm{~m}^{2}$ and the dislocation density both significantly increase (Fig. 6). The refinement of the grains occurs, irrespective of the deformation temperature (Fig. 6). Note that the density of LABs, which were revealed by the TEM technique, is higher by a factor of approximately 10 than the density of LABs, which were detected using the EBSD technique. Therefore, the density of planar LABs with misorientations $<2^{\circ}$ is higher by a factor $\sim 10$ than LABs with misorientations $\geq 2^{\circ}$.

Upon further straining, the deformation microstructure evolves from inhomogeneous lamellar-type toward a granular homogeneous microstructure with more equiaxed crystallites. The dislocation density is remarkably affected by the deformation temperature. At $\varepsilon>1$, the dislocation density tends to saturate at levels of $4 \times 10^{14} \mathrm{~m}^{-2}$ to $9 \times 10^{14} \mathrm{~m}^{-2}$, depending on the temperature (Fig. 6). At $\varepsilon \sim 2$, the formation of deformation microbands aligned along the new SD leads to the subdivision of first-order microbands into subgrains, (sub)grains and grains having nearly rhombic shape (Fig. 3b). The first generation microbands, which are bounded by strain-induced LABs or HABs, appear as wavy lines that are sheared and slipped off by the second (and subsequent) generation microbands delimited by LABs. This process occurs heterogeneously and leads to the formation of separate chains of subgrains, (sub)grains and grains (Fig. 3c). The volume fraction of these chains gradually increases with strain and clearly correlates with the strain dependence of ultrafine grain fraction (Fig. 7). The remnants of the initial grains contain a significant fraction of LABs with misorientations $<15^{\circ}$ (Fig. $3 \mathrm{~d}$ and e). The spacing of dislocation boundaries revealed by the TEM technique and, correspondingly, their densities are almost independent of strain (Fig. 4). In contrast, the density of boundaries with misorientations $\geq 2$ grows significantly at $\varepsilon \leq 4$ (Fig. 6). It is apparent that most of the LABs with initial misorientations $<2^{\circ}$ within the microbands acquire misorientation $\geq 2^{\circ}$, while the misorientations of LABs within remnants of initial grains remain essentially unchanged (Fig. 3b and c).

The number of ultrafine grains composing the chains increases with increasing strain, which results in the formation of a necklace-like microstructure at $\varepsilon \sim 4$ (Fig. 3c). The island remainders of the original coarse grains are subdivided by dislocation boundaries (Fig. 4c). This process is accompanied by shifts of misorientation distribution and average misorientation to higher misorientations (Figs. 5 and 7). It is apparent that the large fraction of LABs in the misorientation distribution (Fig. 5) and the gradual increase in boundary density (Fig. 6) are observed because some planar LABs with initial misorientation $<2^{\circ}$ located within the remnant islands acquire misorientations $\geq 2^{\circ}$ with increasing strain. The development of equiaxed grains and (sub)grains was not accompanied by a decrease in the density of interior dislocations, which remains essentially unchanged with strain in the range $\varepsilon \leq 8$ (Fig. 6). Nanoscale $\mathrm{Cr}$ particles effectively pin the gliding dislocation (Fig. $4 \mathrm{~b}$ and d). Therefore, in the strain interval of $1-4$, the lattice dislocations emitted by sources were completely consumed for the increase in misorientations of LABs above $2^{\circ}$, as well as for the transformation of planar LABs to HABs. In the strain range of 4-8, the formation of new LABs with misorientations $\geq 2^{\circ}$ is accelerated and newly generated dislocations are consumed for increasing misorientation of LABs, which leads to their transformation to HABs (Figs. 5 and 7). A dynamic equilibrium between the number of dislocations emitted by sources and the number of dislocations trapped by boundaries is established (Fig. 6). No additional formation of LABs with misorientations $<2^{\circ}$ occurs.

At $\varepsilon \sim 8$, the propagation of ultrafine-grained volumes through the entire sample diminishes the volume fraction of the remnants of initial grains (Fig. 3d). The deformation structure becomes more uniform and consists of well-defined bands of grains and (sub) 

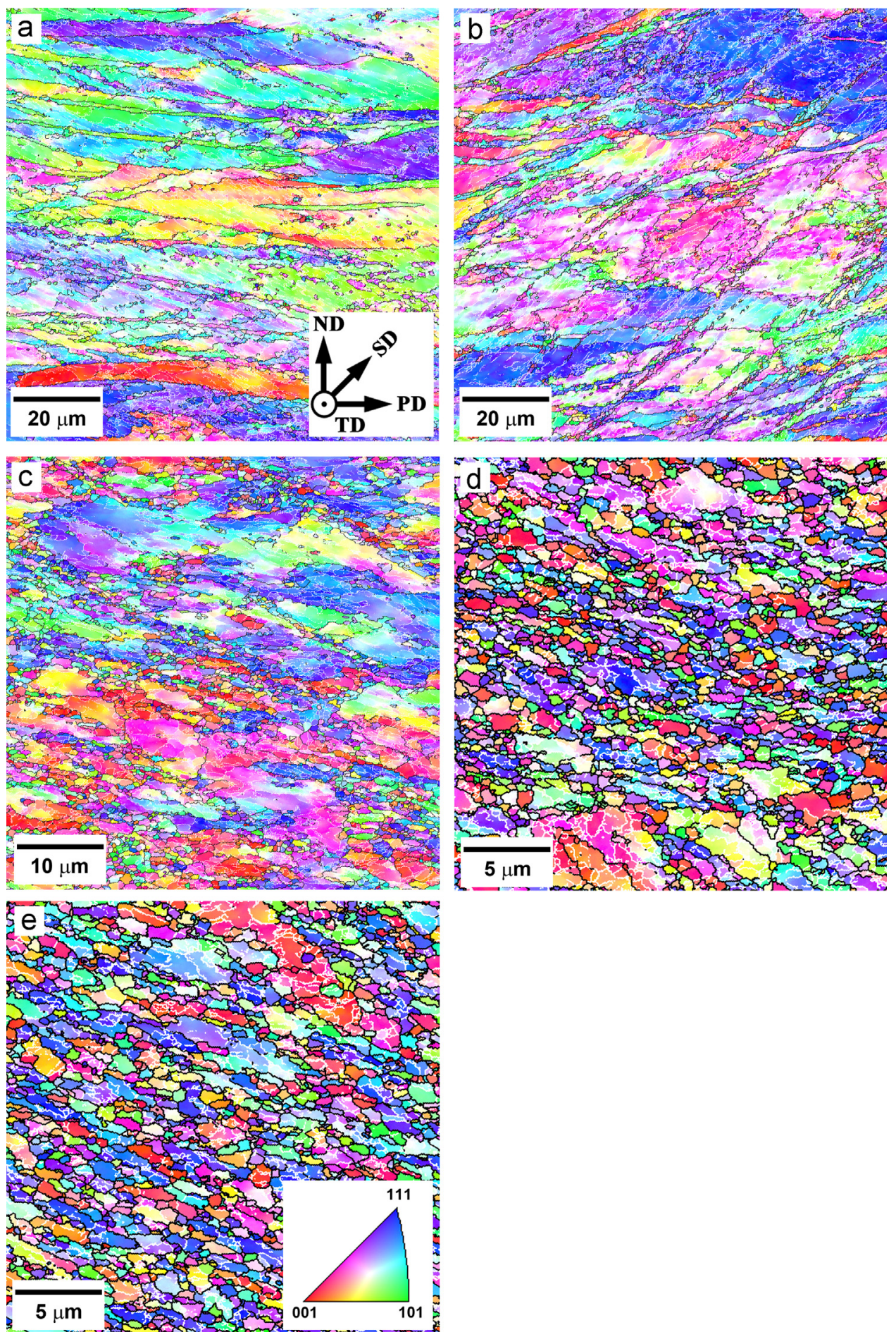

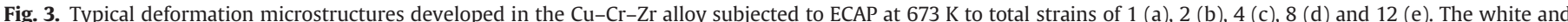

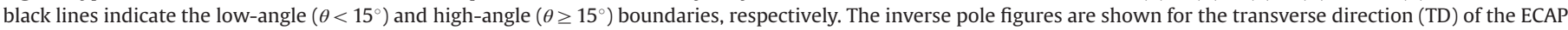
billets.

grains aligned and elongated along a nearly right angle to the SD. At $\varepsilon \sim 12$, the chains of grains and (sub)grains occupy almost the entire sample volume (Fig. 3e). The volume fraction of remnant islands of initial grains decreases, and the fraction of HABs becomes $\geq 60 \%$ (Fig. 7); therefore, this structure can be considered as ultrafine grained $[30,44,45]$. The grain size decreases from $\sim 0.8 \mu \mathrm{m}$ to $\sim 0.6 \mu \mathrm{m}$ with increasing strain from $\varepsilon \sim 8$ to $\varepsilon \sim 12$ (Fig. 6). This process is accompanied by an insignificant decrease in the density of forest dislocations, along with the boundary density remaining constant (Fig. 6). Therefore, most of the dislocations emitted by sources are consumed for the transformation of LABs to HABs, which leads to the transition from partially grained structure to fully granular deformation structure at large strains (Figs. 3 and 7). At $\varepsilon \sim 12$, the strain-induced boundaries exhibit specific contrast (Fig. 4f), which is typical for non-equilibrium HABs containing a high density of grain boundary dislocations and corrugated portions with facets and steps [24,28,46]. However, these grain boundary defects induce small stress fields [47]. The lattice planes are slightly curved by these fields in the vicinity of non-equilibrium grain boundaries, as suggested by the smooth 

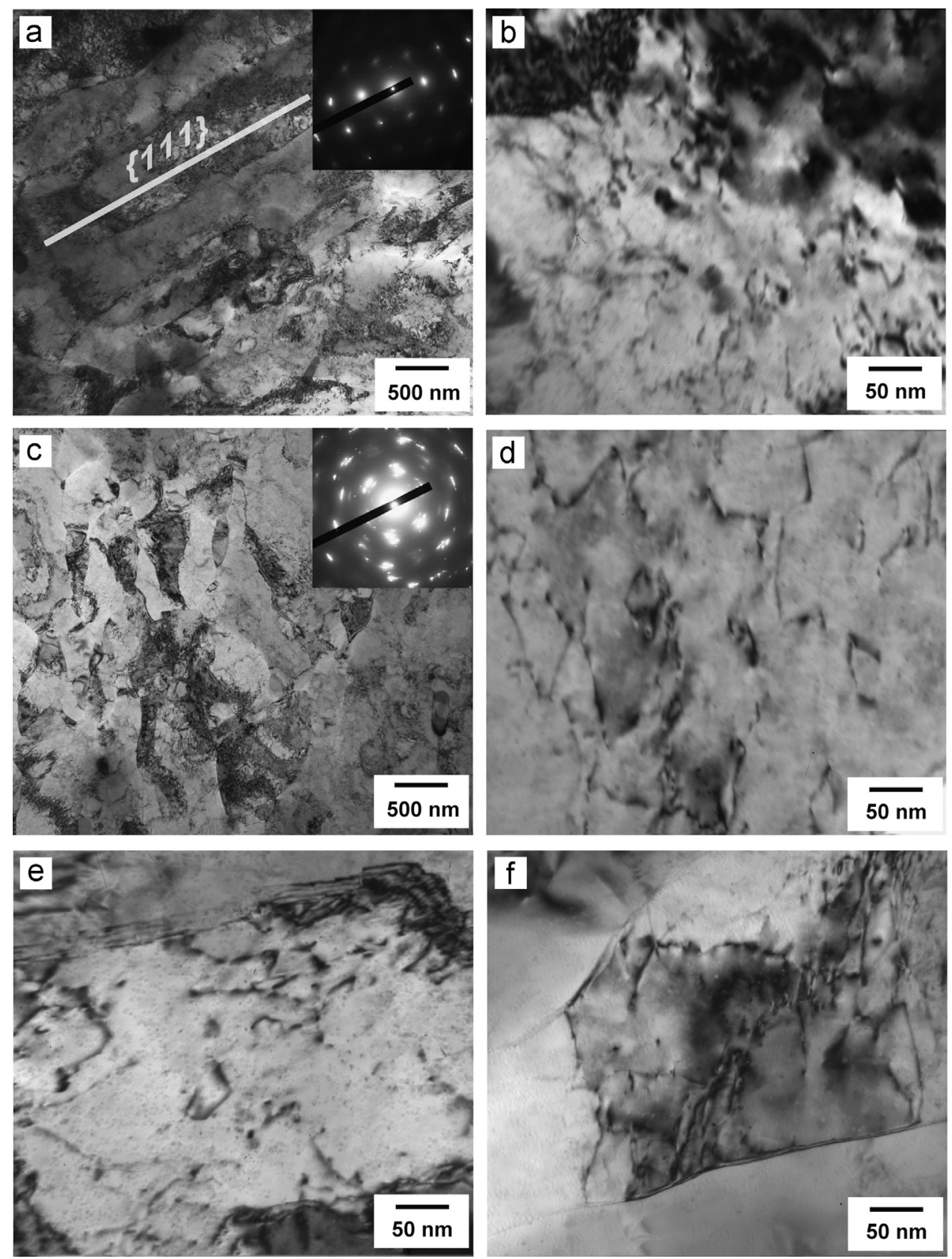

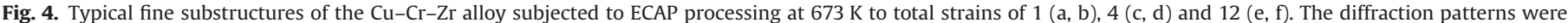
obtained from the areas of $\varnothing 650 \mathrm{~nm}$.

features in the TEM images (Fig. 4e and $\mathrm{f}$ ), which is not typical for other materials $[46,47]$, even pure $\mathrm{Cu}[28,29]$. Note that the distribution of $\mathrm{Cr}$ particles does not remarkably vary with temperature/strain of ECAP processing (Fig. $4 \mathrm{~b}, \mathrm{~d}$ and e).

The fraction of HABs $\left(F_{\mathrm{HAB}}\right)$, the fraction of ultrafine grains $\left(F_{\mathrm{UFG}}\right)$ and the average boundary misorientation $\left(\theta_{\mathrm{av}}\right)$ exhibit a nearly linear increase with strain (Fig. 7), which is typical for cDRX $[7,25,27,30,41,42]$. The strain dependencies of the primary structural parameters do not depend remarkably on the temperature in the interval of $473-673 \mathrm{~K}$. The variations of $F_{\mathrm{HAB}}, F_{\mathrm{UFG}}$ and $\theta_{\mathrm{av}}$ with strain can be approximately expressed as $F_{\mathrm{HAB}}=0.2+0.04 \varepsilon$, $F_{\mathrm{UFG}}=0.07 \varepsilon$ and $\theta_{\mathrm{av}}=12+1 \varepsilon$, respectively, for the strain range of $1 \leq \varepsilon \leq 8$.

The development of the ultrafine grains with a size of less than $2 \mu \mathrm{m}$ during ECAP at different temperatures in the range of 473$673 \mathrm{~K}$ is quantitatively shown in Fig. 8 as the fine grain portions of the grain size distributions. The first ECAP pass does not lead to ultrafine grain formation. Small peaks corresponding to the ultrafine grains can be recognized on the grain size distributions for the samples subjected to 4 ECAP passes. The number of ultrafine grains increases significantly during the subsequent straining, which leads to an increase in the fraction of ultrafine grains to above 0.5 at a total strain of 8 . Note that temperature scarcely affects the grain refinement kinetics under ECAP. Nearly the same grain size distributions are developed at the same strains, irrespective of the processing temperature.

\subsection{Tensile behavior}

The engineering tensile stress-strain curves of the $\mathrm{Cu}-\mathrm{Cr}-\mathrm{Zr}$ alloy in the peak aged condition and subjected to ECAP with different strains at 473-673 K are shown in Figs. 9 and 10, and the 


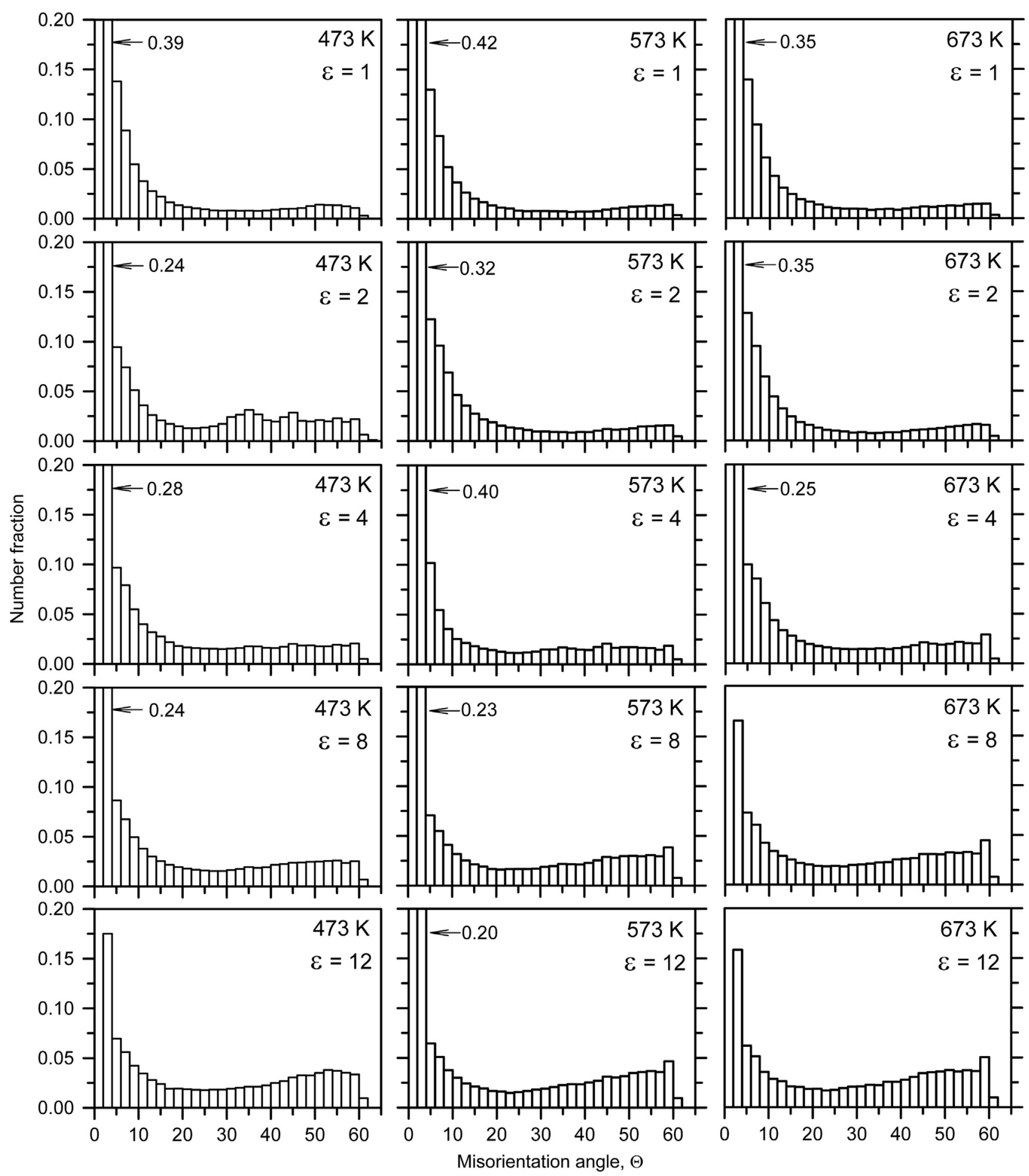

Fig. 5. The misorientation distributions for the $\mathrm{Cu}-\mathrm{Cr}-\mathrm{Zr}$ alloy subjected to ECAP processing. The scale of axes is the same for all histograms.

mechanical properties, i.e., the YS $\left(\sigma_{0.2}\right)$, the ultimate tensile strength (UTS) and the total elongation-to-failure $(\delta)$, are presented in Table 1 . In the peak aged condition, extensive strain hardening initially occurs (Fig. 9). After reaching a maximum stress at $\varepsilon \sim 0.14$, the flow stress continuously decreases until fracture. A well-defined peak in flow stress is observed, and no steady-state flow occurs. The ECAP processing results in a specific type of $\sigma-\varepsilon$ curve, which is typical for peak aged alloys (Fig. 10) [48]. The maximum stress is achieved soon after yielding. After ECAP processing at $673 \mathrm{~K}$, the apparent steady state is observed, and the flow stress starts to decrease until fracture after $\varepsilon \sim 0.04$.
After ECAP processing at 473 and $573 \mathrm{~K}$, the flow stress continuously decreases after the peak stress. No remarkable effect of strain imposed on the alloy under ECAP on the shape of the $\sigma-\varepsilon$ curves was found. Note that the shape of the $\sigma-\varepsilon$ curves in the present $\mathrm{Cu}-\mathrm{Cr}-\mathrm{Zr}$ alloy and pure $\mathrm{Cu}[28]$ is essentially the same for all conditions.

The strain imposed by ECAP in the alloy strongly affects the strength and ductility (Fig. 10). The YS increase is $+102 \%$ and $+125 \%$ after one pass at $673 \mathrm{~K}$ and $473 \mathrm{~K}$, respectively (Table 1 ). The first pass provides significant strengthening of the $\mathrm{Cu}-\mathrm{Cr}-\mathrm{Zr}$ alloy; the efficiency in the strengthening increases with a decrease in the ECAP 


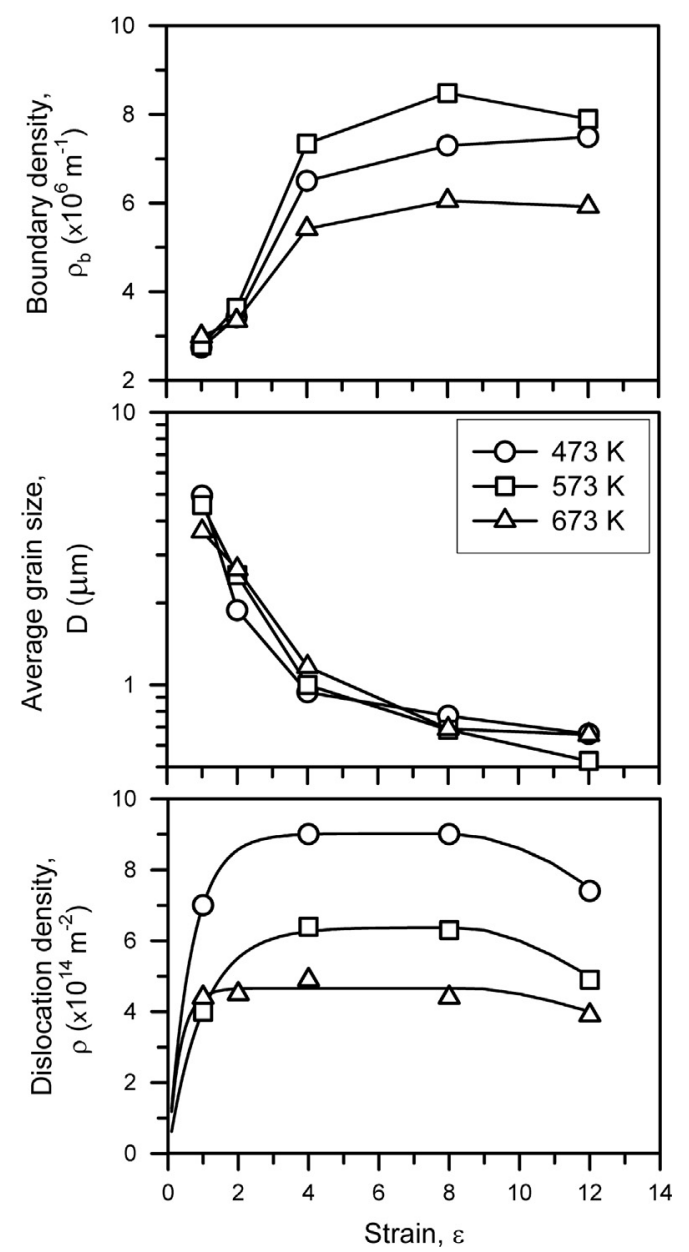

Fig. 6. The ECAP effect on the structural parameters: the density of boundaries with misorientations of $\theta \geq 2\left(\rho_{\mathrm{b}}\right)$, the average grain size $(D)$ and the dislocation density $(\rho)$ in the $\mathrm{Cu}-\mathrm{Cr}-\mathrm{Zr}$ alloy.

temperature. The YS increases from $215 \mathrm{MPa}$ in the initial peak aged state to $435 \mathrm{MPa}$ or $485 \mathrm{MPa}$ after ECAP at $673 \mathrm{~K}$ or $473 \mathrm{~K}$, respectively. The subsequent ECAP processing to $\varepsilon \sim 4$ provides an additional $\sim 50 \mathrm{MPa}$ increment in the YS irrespective of the temperature. Upon further straining to $\varepsilon \sim 8$, the YS and the UTS values remain unchanged. The effect of ECAP temperature on the YS after $\varepsilon \sim 8$ is negligibly small. The YS varies from 480 to $535 \mathrm{MPa}$ with a decrease in temperature from 673 to $473 \mathrm{~K}$. The strength tends to decrease with an increase in strain to $\varepsilon \sim 12$, especially after ECAP processing at the relatively high temperature of $673 \mathrm{~K}$ (Table 1 ). At $473 \mathrm{~K}$, increasing the strain from $\sim 8$ to $\sim 12$ leads to a $-4 \%$ decrease in the YS and no change in the UTS, while at $673 \mathrm{~K}$, this additional strain leads to a $-10 \%$ and $-2 \%$ decrease in the YS and the UTS, respectively.

The strengthening by ECAP to strains of $\varepsilon \leq 8$ is accompanied by degradation in plasticity from $\sim 25 \%$ in the initial state to $\sim 10 \pm 1.5 \%$, irrespective of temperature/strain conditions. An exception is observed after ECAP to strains of $\sim 1$ or $\sim 2$ at $673 \mathrm{~K}$, when the elongation is 15$16 \%$ (Table 1). However, upon further straining, the total elongation decreases to $\sim 10 \%$. An increase in the total elongation to $12-15 \%$ is observed after ECAP to $\varepsilon \sim 12$ at all temperatures. However, the uniform elongation decreases drastically, especially after ECAP processing at $473-573 \mathrm{~K}$. The uniform elongation is $3-4 \%$ in the samples subjected to ECAP processing at $673 \mathrm{~K}$ and does not exceed $1 \%$ after ECAP processing at $473 \mathrm{~K}$. Therefore, ECAP processing of the $\mathrm{Cu}-\mathrm{Cr}-\mathrm{Zr}$ alloy at 473-673 $\mathrm{K}$ shortens the hardening stage. In contrast to the original sample, the necking in the ECAP-processed samples occurs at an early stage of tension, leading to a gradual decrease in the stress

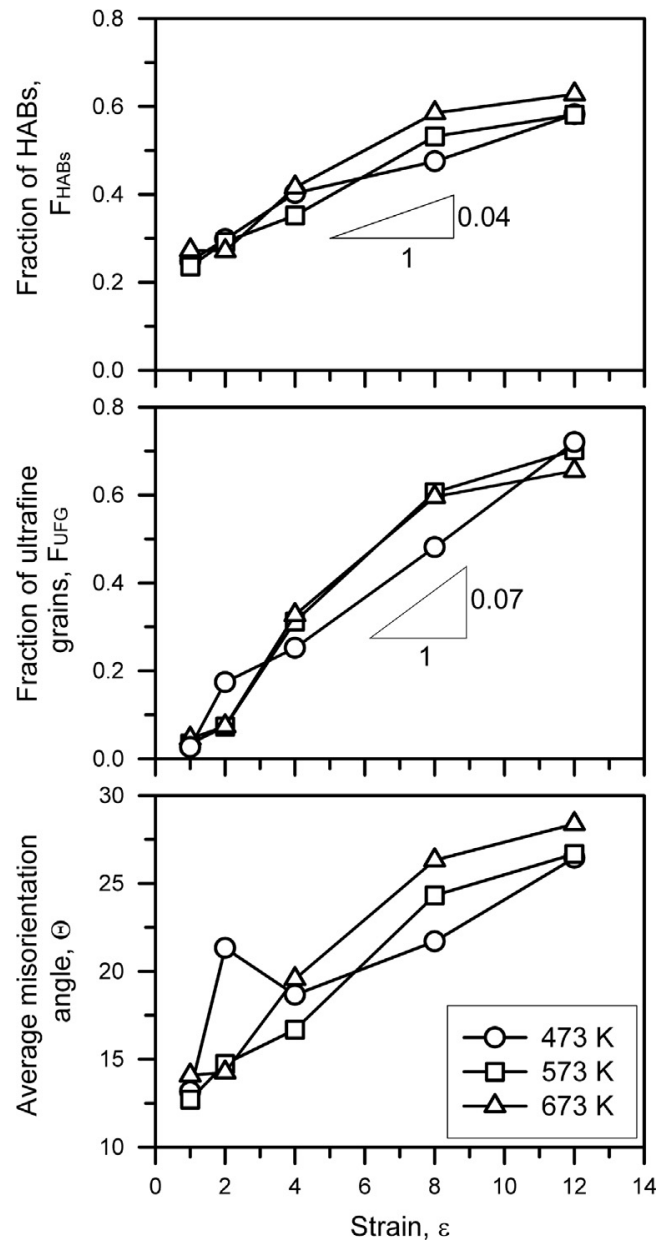

Fig. 7. The effect of strain on the fraction of HABs $\left(F_{\mathrm{HABs}}\right)$, the fraction of ultrafine grains $\left(F_{\mathrm{UFG}}\right)$ and the average misorientation $(\theta)$ in the $\mathrm{Cu}-\mathrm{Cr}-\mathrm{Zr}$ alloy subjected to ECAP processing at temperatures of $473-673 \mathrm{~K}$.

during the tensile tests. As a result, the UTS values are very close to the $\mathrm{YS}$ in the $\mathrm{Cu}-\mathrm{Cr}-\mathrm{Zr}$ alloy subjected to ECAP processing.

\subsection{Electrical conductivity}

Fig. 11 summarizes the effect of ECAP on the electrical conductivity. The first and second passes lead to a remarkable decrease in the electrical conductivity. Upon further straining, the electrical conductivity of samples processed at $473 \mathrm{~K}$ and $673 \mathrm{~K}$ remains unchanged, while the electrical conductivity of samples processed at $573 \mathrm{~K}$ tends to degrade. The samples processed at $673 \mathrm{~K}$ are characterized by the highest electrical conductivity in almost all of the studied strain range.

\section{Discussion}

\subsection{Deformation microstructures}

Inspection of experimental data reveals that the microstructural evolution in the $\mathrm{Cu}-\mathrm{Cr}-\mathrm{Zr}$ alloy is typical of the occurrence of cDRX at relatively low temperatures [30]. The deformation structures evolved in the present alloy in the temperature interval 473$673 \mathrm{~K}$ and those of pure copper subjected to intense plastic straining at ambient temperature $[28,29]$ are nearly the same. In contrast to pure $\mathrm{Cu}$ subjected to ECAP processing at ambient temperature $[28,49]$, the recovery processes do not develop remarkably in the present $\mathrm{Cu}-\mathrm{Cr}-\mathrm{Zr}$ alloy, even at $673 \mathrm{~K}$. 

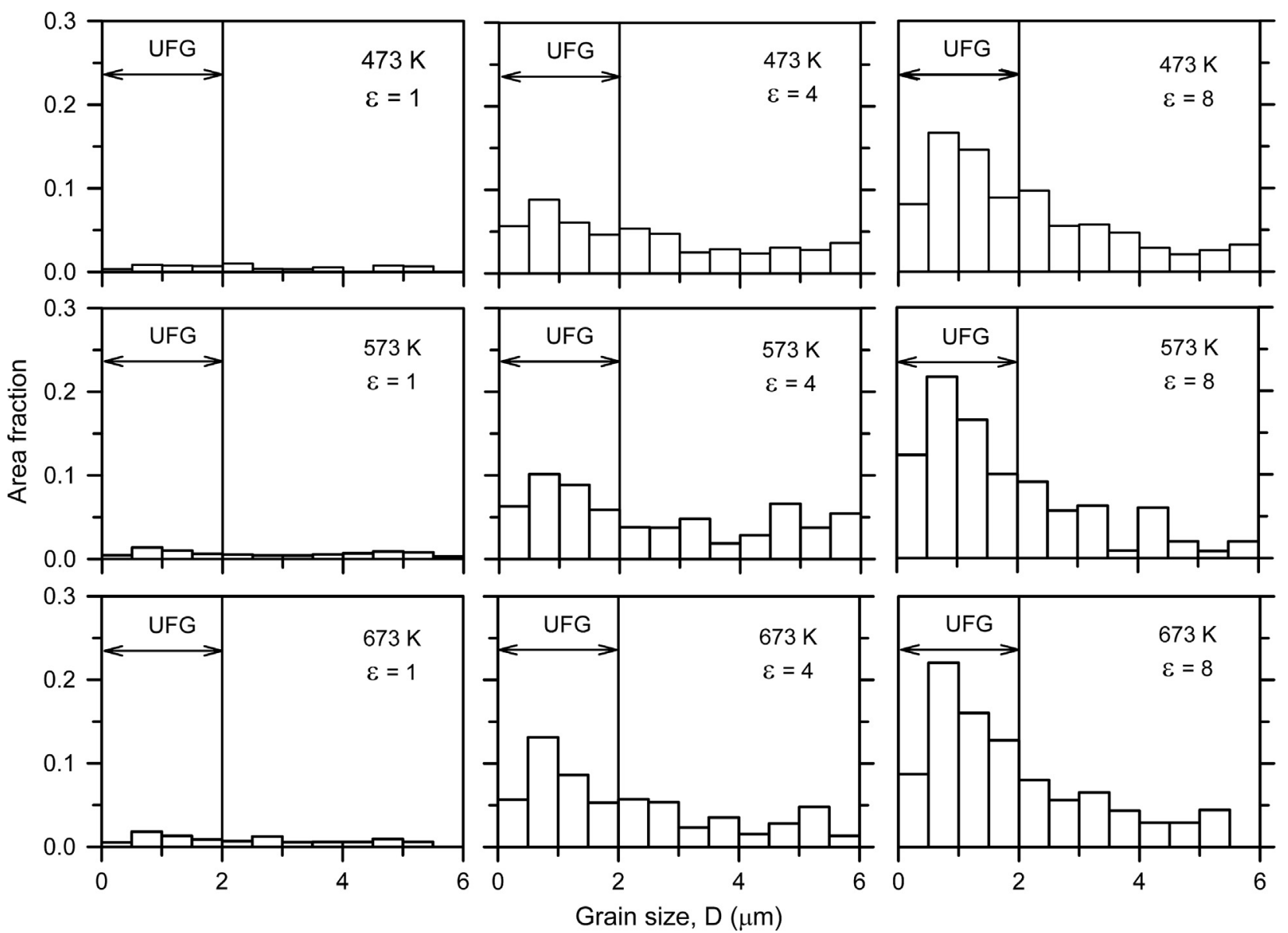

Fig. 8. Grain size distributions for the $\mathrm{Cu}-\mathrm{Cr}-\mathrm{Zr}$ alloy processed by ECAP at $473-673 \mathrm{~K}$ to total strains of $\varepsilon \sim 1, \varepsilon \sim 4$ and $\varepsilon \sim 8$.

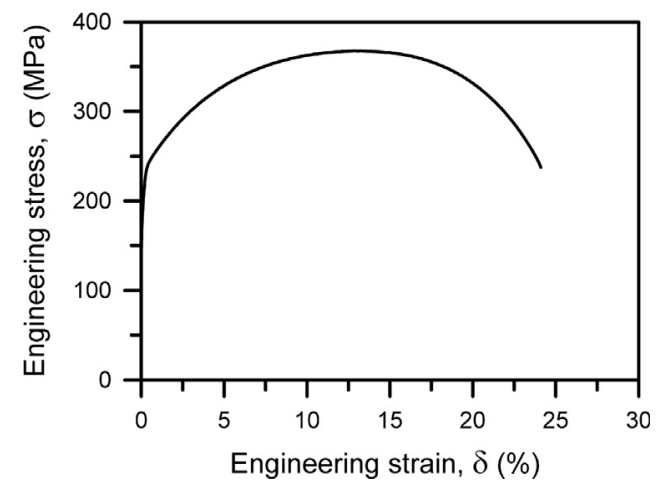

Fig. 9. Engineering stress-engineering strain curve obtained by tensile test of the $\mathrm{Cu}-\mathrm{Cr}-\mathrm{Zr}$ alloy in peak-aged condition.

Therefore, the deformation structures in this alloy are typical for cold working. As a result, there is little effect of temperature on the microstructural evolution; thus, attention will be focused on deformation structures evolved at $673 \mathrm{~K}$ and their effect on mechanical properties and electrical conductivity for simplicity.

Typical deformation structures are schematically shown in Fig. 12. At small strains of $\varepsilon \leq 2$, the deformation structures consist of elongated grains subdivided by LABs with misorientations $\leq 3^{\circ}$ into lamellas, which is a lamellar structure with a high fraction of LABs with small misorientation. In the range of medium strains of $4-8$, the mantle of the submicrometer-scale grains evolves around the remnants of initial grains, which are subdivided by LABs into crystallites of rhomboid-like shape. Some planar LABs acquire a misorientation $\geq 3^{\circ}$, resulting in a mixed structure consisting of subgrains, (sub)grains and
Table 1

Mechanical properties of the $\mathrm{Cu}-\mathrm{Cr}-\mathrm{Zr}$ alloy in peak-aged condition and processed by ECAP under the indicated conditions.

\begin{tabular}{|c|c|c|c|c|}
\hline \multicolumn{2}{|l|}{ Condition } & $\begin{array}{l}\text { Yield strength, } \\
\left(\sigma_{0.2}\right) \mathrm{MPa}\end{array}$ & $\begin{array}{l}\text { Ultimate tensile } \\
\text { strength, (UTS) MPa }\end{array}$ & $\begin{array}{l}\text { Elongation, } \\
(\delta) \%\end{array}$ \\
\hline \multicolumn{2}{|c|}{ Initial state (peak-aged) } & \multirow[t]{2}{*}{215} & \multirow[t]{2}{*}{365} & \multirow[t]{2}{*}{24.1} \\
\hline $\begin{array}{l}\text { ECAP } \\
\text { temperature, } \\
\mathrm{K}\end{array}$ & $\begin{array}{l}\text { Number } \\
\text { of passes }\end{array}$ & & & \\
\hline \multirow[t]{5}{*}{473} & 1 & 485 & 490 & 9.3 \\
\hline & 2 & 495 & 525 & 11.0 \\
\hline & 4 & 525 & 535 & 9.1 \\
\hline & 8 & 535 & 550 & 9.3 \\
\hline & 12 & 515 & 550 & 14.5 \\
\hline \multirow[t]{5}{*}{573} & 1 & 470 & 475 & 9.9 \\
\hline & 2 & 475 & 500 & 12.5 \\
\hline & 4 & 515 & 525 & 9.7 \\
\hline & 8 & 525 & 540 & 9.7 \\
\hline & 12 & 485 & 520 & 12.0 \\
\hline \multirow[t]{5}{*}{673} & 1 & 435 & 465 & 16.5 \\
\hline & 2 & 445 & 485 & 15.0 \\
\hline & 4 & 480 & 500 & 10.5 \\
\hline & 8 & 480 & 500 & 11.0 \\
\hline & 12 & 430 & 465 & 16.0 \\
\hline
\end{tabular}

grains having a nearly equiaxed shape. At large strains of $\varepsilon \sim 12$, the ultrafine-grained structure develops. The new grains exhibit an elongated shape and result from subdivision of lamellar-type grains by transverse planar LABs, part of which acquires high-angle misorientation corresponding to a granular-type structure. Note that the 


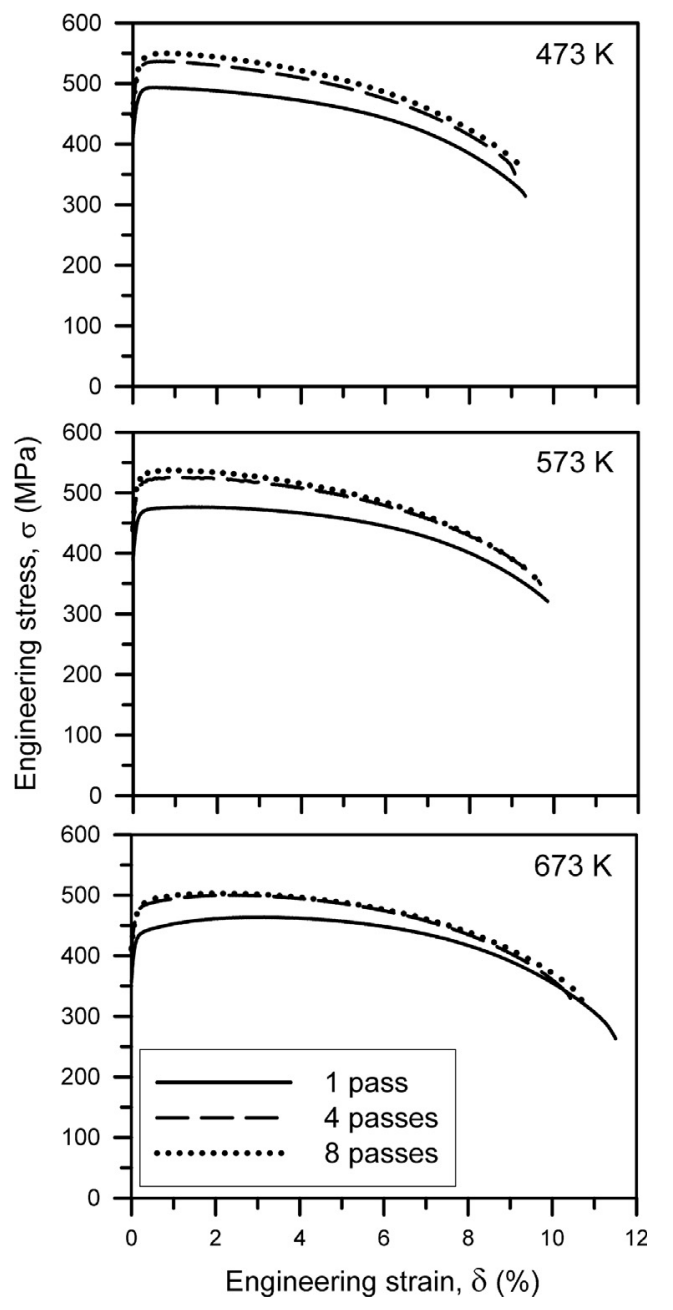

Fig. 10. Engineering stress-engineering strain curves obtained by tensile test of the $\mathrm{Cu}-\mathrm{Cr}-\mathrm{Zr}$ alloy subjected to ECAP processing at temperatures of $473-673 \mathrm{~K}$

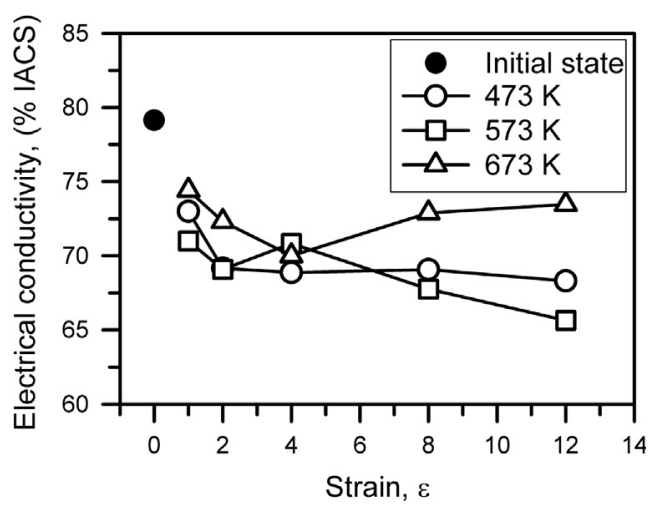

Fig. 11. The influence of large strain deformation on the electrical conductivity of the $\mathrm{Cu}-\mathrm{Cr}-\mathrm{Zr}$ alloy.

structural parameters of the studied material are close to those observed in pure copper subjected to ECAP at room temperature [28]. No static recrystallization or grain coarsening occurs, even at $673 \mathrm{~K}$. As a result, the high dislocation densities that evolved during plastic working remain in ultrafine-grained structures. The dislocation density in the present alloy is only slightly higher than that in $\mathrm{Cu}$ subjected to ECAP at ambient temperature [28]. The next section describes the relationship between the deformation structure features and the YS in the present $\mathrm{Cu}-\mathrm{Cr}-\mathrm{Zr}$ alloy and in copper [28] in which deformation structures after the same number of passes are also essentially the same.
SMALL STRAINS MEDIUM STRAINS LARGE STRAINS

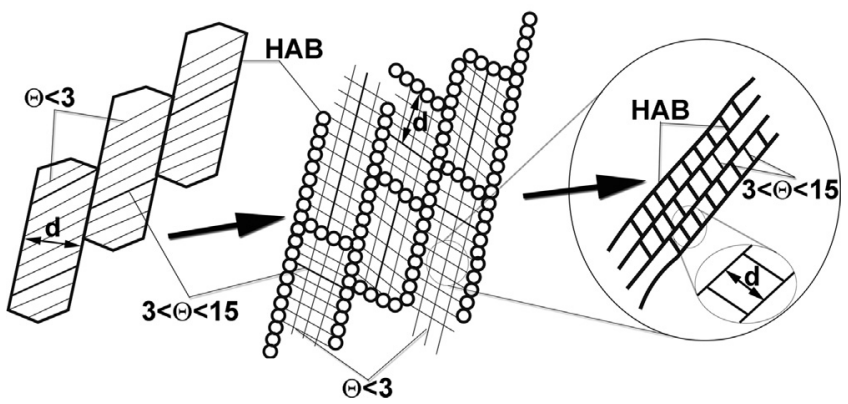

Fig. 12. Schematic illustration of the microstructural evolution in the $\mathrm{Cu}-\mathrm{Cr}-\mathrm{Zr}$ alloy subjected to ECAP processing.

\subsection{Strengthening mechanisms}

Commonly, the flow stress of metallic materials subjected to plastic deformation can be related to the grain size by an equation, which has the same form as the Hall-Petch relationship (1) [50,51], assuming that the first term corresponds to the flow stress of the grain interior and the second one represents an additional strengthening by grain boundaries [52]. Therefore, an increase in the YS of the $\mathrm{Cu}-\mathrm{Cr}-\mathrm{Zr}$ alloy and copper [28] due to intense plastic straining can be associated with the two mechanisms that contribute to the overall strength: (i) the grain boundary strengthening, which is related to the distance between the HABs or LABs with moderate misorientations [33] that are impenetrable obstacles to gliding dislocations, and (ii) the dislocation strengthening related to the high dislocation density within grains and (sub) grains. These strength contributions are assumed to be independent and linearly additive [53,54]. The dispersion hardening should not affect the increase in the YS because no effect of ECAP on the dispersions of the secondary phases was observed. However, the dispersion of the nanoscale $\mathrm{Cr}$ particles is responsible for the difference between the $\mathrm{YS}$ of the $\mathrm{Cu}-\mathrm{Cr}-\mathrm{Zr}$ alloy and of copper [28] because there is no significant difference in the parameters of the deformation structures between these two materials. Note that the grain sizes for the $\mathrm{Cu}-\mathrm{Cr}-\mathrm{Zr}$ alloy were determined using the OIM micrographs, while those for the pure copper were obtained via TEM observations [28]. Therefore, the contribution of the grain size strengthening to the overall YS of pure $\mathrm{Cu}$ may be overestimated because some boundaries with very small misorientations were taken into account.

In general, the YS $\left(\sigma_{0.2}\right)$ of metals and alloys processed by severe plastic deformation can be expressed by a modified HallPetch-type relationship in the following form [53-56]:

$\sigma_{0.2}=\sigma_{0}+K_{\mathrm{H}} d^{-0.5}+M \alpha G b \rho^{0.5}$

where $\sigma_{0}$ is the friction stress for $\mathrm{Cu}$ [28] or the sum of friction stress and the precipitation strengthening stress for the present $\mathrm{Cu}-\mathrm{Cr}-\mathrm{Zr}$ alloy, $\mathrm{G}$ is the shear modulus, $b$ is the Burgers vector, $\rho$ is the forest dislocation density, $M$ is the Taylor factor determined from EBSD data $(M=3.17$ for small strains, $M=3.13$ for medium strains, and $M=3.09$ for large strains), $\alpha \approx 0.2$ [57] is a numerical factor, and $d$ is the effective grain size. The $d$ values were calculated by two methods [37]: (1) the average distance between any HABs and (2) the distance between any boundaries with a misorientation $\geq 3^{\circ}$ (because LABs with misorientation angles greater than $3^{\circ}$ produced by cold working may act as conventional grain boundaries in terms of their strength contribution) [35-37]. In the case of the lamellar structure evolved at small strains (Fig. 12), the effective grain size was calculated as twice the distance between planar boundaries [54]. The values of $\sigma_{0}$ and $K_{\mathrm{H}}$ were determined using the least-squares method on the plots 
of the YS against the $d$ values (Fig. 13, Table 2). Note that the dislocation density calculated as a sum of forest dislocations and the dislocations stored in the LABs with misorientation $\leq 3^{\circ}$ in accordance with the approach described in $[37,54,58]$ is an overestimation. In this case, the stresses attributed to dislocation strengthening, i.e., the absolute values of the third term in Eq. (2), are higher than the experimental YS. As a result, all of the calculated values in Table 2 were obtained only for the density of forest dislocations (Fig. 6). Table 2 represents the contributions of different strengthening mechanisms to the overall strength, taking into account only the forest dislocation density. The $d$ values taken as the distance between all boundaries with misorientation $\geq 3^{\circ}$ are found to describe adequately the contributions of different strengthening mechanisms to the overall YS for both materials. The use of the $d$ values as the distance between HABs provides an unreasonably low contribution of grain size strengthening to the overall YS (Table 2). Thus, the strengthening mechanisms operating in the $\mathrm{Cu}-\mathrm{Cr}-\mathrm{Zr}$ alloy and pure $\mathrm{Cu}[28]$ will be compared with the presumption that LABs with misorientation $\geq 3^{\circ}$ provide the same contribution to the grain size strengthening as HABs [35,36].

It is observed (Tables 1 and 2) that a dispersion of $\mathrm{Cr}$ nanoscale coherent particles provides a $+395 \%$ increase $(144.5 \mathrm{MPa})$ in the $\sigma_{0}$ value. An estimation of the contribution of the precipitation strengthening is associated with the well-known Orowan bowing [36]:

$\sigma_{p}=0.84 M G b / \lambda$

where $\lambda$ is the inter-particle spacing that predicts the $\sigma_{0}$ increment, which is two times larger than the experimental $\sigma_{0}$.

\section{a}

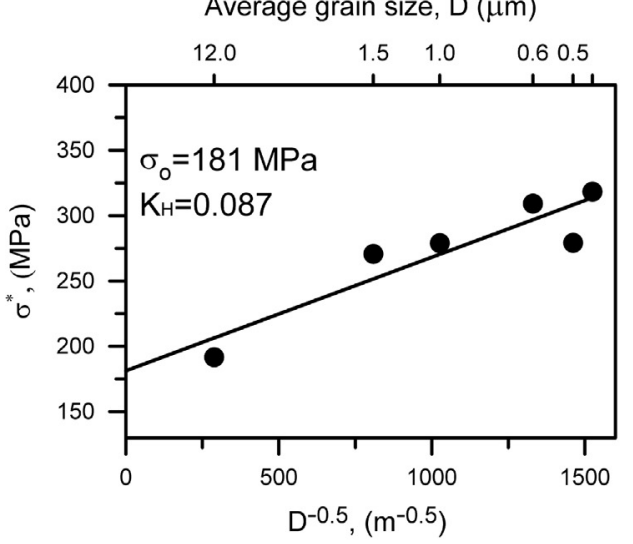

b

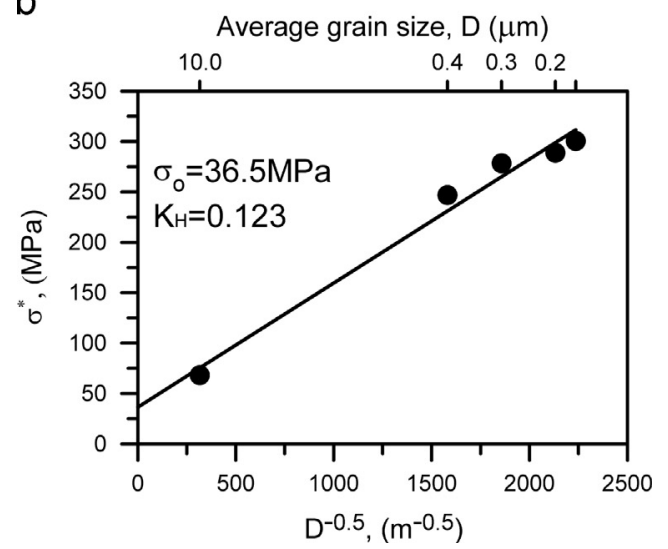

Fig. 13. Relationship between the grain size and $\sigma^{*}\left(\sigma^{*}=\sigma_{0.2}-M \alpha G b \rho^{0.5}\right)$ in the $\mathrm{Cu}-$ $\mathrm{Cr}-\mathrm{Zr}$ alloy processed by ECAP at $673 \mathrm{~K}$ (a) and a pure Cu processed by ECAP at ambient temperature [28] (b).
Table 2

Contribution of the strengthening mechanisms in the $\mathrm{Cu}-\mathrm{Cr}-\mathrm{Zr}$ alloy and in pure $\mathrm{Cu}$ [28]. The grain size was calculated as the distance between boundaries with $\Theta \geq 3^{\circ}$ (boldface) or $\Theta \geq 15^{\circ}$ (number in brackets).

\begin{tabular}{|c|c|c|c|c|c|c|}
\hline \multicolumn{2}{|c|}{ ECAP passes } & \multicolumn{4}{|c|}{ Calculated strengthening (MPa) } & \multirow{2}{*}{$\begin{array}{l}\text { Experimental yield } \\
\text { stress }\left(\sigma_{0.2}\right), \mathrm{MPa}\end{array}$} \\
\hline & & $\sigma_{0}$ & $\begin{array}{l}\text { Grain- } \\
\text { boundary }\end{array}$ & Dislocation & Total & \\
\hline \multirow[t]{2}{*}{1} & $\begin{array}{l}\text { Present } \\
\text { study }\end{array}$ & $\begin{array}{l}\mathbf{1 8 1} \\
(202)\end{array}$ & $70(47)$ & 165 & $\begin{array}{l}\mathbf{4 1 6} \\
(414)\end{array}$ & 435 \\
\hline & $\begin{array}{l}\text { Dalla Torre } \\
\text { et al. [28] }\end{array}$ & 36.5 & 194 & 95 & 325.5 & 342 \\
\hline \multirow[t]{2}{*}{2} & $\begin{array}{l}\text { Present } \\
\text { study }\end{array}$ & $\begin{array}{l}\mathbf{1 8 1} \\
(202)\end{array}$ & $89(55)$ & 166 & $\begin{array}{l}436 \\
(423)\end{array}$ & 445 \\
\hline & $\begin{array}{l}\text { Dalla Torre } \\
\text { et al. [28] }\end{array}$ & 36.5 & 275 & 107 & 418.5 & 407 \\
\hline \multirow[t]{2}{*}{4} & $\begin{array}{l}\text { Present } \\
\text { study }\end{array}$ & $\begin{array}{l}\mathbf{1 8 1} \\
(202)\end{array}$ & $116(83)$ & 171 & $\begin{array}{l}\mathbf{4 6 8} \\
(456)\end{array}$ & 480 \\
\hline & $\begin{array}{l}\text { Dalla Torre } \\
\text { et al. [28] }\end{array}$ & 36.5 & 262 & 126 & 424.5 & 415 \\
\hline \multirow[t]{2}{*}{8} & $\begin{array}{l}\text { Present } \\
\text { study }\end{array}$ & $\begin{array}{l}\mathbf{1 8 1} \\
(202)\end{array}$ & $133(108)$ & 162 & $\begin{array}{l}\mathbf{4 7 6} \\
(472)\end{array}$ & 480 \\
\hline & $\begin{array}{l}\text { Dalla Torre } \\
\text { et al. [28] }\end{array}$ & 36.5 & 228 & 107 & 371.5 & 385 \\
\hline 12 & $\begin{array}{l}\text { Present } \\
\text { study }\end{array}$ & $\begin{array}{l}\mathbf{1 8 1} \\
(202)\end{array}$ & $127(111)$ & 151 & $\begin{array}{l}\mathbf{4 5 9} \\
(464)\end{array}$ & 430 \\
\hline
\end{tabular}

Therefore, the strengthening associated with the dispersed $\mathrm{Cr}$ particles should be different from the Orowan mechanism. The shearing mechanism is the most probable one for the interaction between gliding dislocations and the $\mathrm{Cr}$ particles. It is known [5861] that three main factors contributing to the overall dispersion hardening associated with shearing exist: the coherency strengthening, the modulus strengthening and the chemical strengthening attributed to interfacial strengthening and anti-phase boundary strengthening [58]. The chemical strengthening is not important in the case of coherent $\mathrm{Cr}$ particles because an anti-phase boundary does not form during the shearing. Thus, the main dispersion strengthening mechanisms are coherency strengthening and modulus strengthening [58-62]. The former can be evaluated as

$\sigma_{\text {coh }}=8.4 M G(\varepsilon)^{1.5}\left(\frac{N}{b}\right)^{0.5} r^{0.5}$

where $N$ is the number of precipitates intersecting unit area, $\varepsilon$ is the misfit strain, and $r$ is the mean radius of precipitates; and the latter can be estimated as

$\sigma_{\text {mod }}=\left(0.05\left(G_{\mathrm{Cr}}+G_{\mathrm{Cu}}\right) b^{2}\left(\frac{r}{b}\right)^{0.85}\right) / S$

where $S$ is the area of intersected particle surface. The values of coherency strengthening of $\sigma_{\mathrm{coh}}=79 \mathrm{MPa}$ and modulus strengthening of $\sigma_{\text {mod }}=118 \mathrm{MPa}$ are obtained for the present alloy. The $\mathrm{Cr}$ dispersoids are relatively hard because the shear modulus for $\mathrm{Cr}$ (118 GPa) is higher than that for $\mathrm{Cu}(48.6 \mathrm{GPa}$ ) by a factor of $\sim 2.38$ and a shearing dislocation must be additionally forced to overcome this particle. To calculate the overall precipitation strengthening effect $\left(\sigma_{\mathrm{p}}\right)$, the different mechanisms are superimposed according to [61]:

$\sigma_{\mathrm{p}}=\left(\frac{f_{\text {shear }}}{f_{\text {total }}}\right)^{0.5} \sqrt{\sigma_{\text {coh }}^{2}+\sigma_{\text {mod }}^{2}}$

where $f_{\text {shear }}$ is the fraction of coherent precipitates and $f_{\text {total }}$ is the total fraction of precipitates. The $f_{\text {shear }} / f_{\text {total }}=1$ was assumed in the present calculation because of the very small size of $\mathrm{Cr}$ dispersoids. The $\sigma_{\mathrm{p}}$ value was calculated to be $142 \mathrm{MPa}$, which is very close to 
the experimental increment of $144.5 \mathrm{MPa}$ in the $\sigma_{0}$ value. The $\sigma_{0}$ for the $\mathrm{Cu}-\mathrm{Cr}-\mathrm{Zr}$ alloy can be calculated by a summation of the precipitation strengthening, $\sigma_{\mathrm{p}}=142 \mathrm{MPa}$, and the friction stress in pure $\mathrm{Cu}, \sigma_{0}=36.5 \mathrm{MPa}$, assuming that the obstacle-controlled and non-obstacle-controlled contributions are linearly additive [63]. The $\sigma_{0}$ calculated from this approach is $178.5 \mathrm{MPa}$, which is very close to the experimental value of $181 \mathrm{MPa}$ obtained for the $\mathrm{Cu}-\mathrm{Cr}-\mathrm{Zr}$ alloy (Fig. 13); this result validates the present analysis.

The contribution of grain size strengthening to overall YS is higher by a factor ranging from 2 to 2.6 than the contribution of dislocation strengthening in the pure $\mathrm{Cu}$ [28], whereas the dislocation strengthening exceeds the grain size strengthening in the $\mathrm{Cu}-\mathrm{Cr}-\mathrm{Zr}$ alloy for all types of deformation structures (Table 2). The role of the grain size strengthening in the overall strengthening is minor for the $\mathrm{Cu}-\mathrm{Cr}-\mathrm{Zr}$ alloy. Similar results have been reported for other structural materials with fcc-lattice [53-56, 64-66], especially for those containing dispersed particles [66]. The dislocation strengthening during large strain deformation has been shown to increase rapidly as strain increases and became the major contributor to the total strength of ultrafine grained materials processed by severe plastic deformation. Moreover, the presence of $\mathrm{Cr}$ particles leads to a decrease in the $K_{\mathrm{H}}$ value that hinders the efficiency of Hall-Petch strengthening in the $\mathrm{Cu}-\mathrm{Cr}-\mathrm{Zr}$ alloy in comparison with pure $\mathrm{Cu}$ [28]. It is apparent that hindering dislocation glide by the $\mathrm{Cr}$ dispersoids within crystallites affects the Hall-Petch relationship. The dislocation strengthening plays a major role in the overall strengthening of the $\mathrm{Cu}-\mathrm{Cr}-\mathrm{Zr}$ alloy via intense plastic straining (Table 2). The dislocation strengthening is primarily responsible for the high strength of ultrafine-grained copper alloys, which contains a dispersion of nanoscale coherent particles, processed by severe plastic deformation. As a result, the highest YS is achieved at low deformation temperatures, at which the highest dislocation density evolves (Table 1, Fig. 6). Note that the ductility of the $\mathrm{Cu}-\mathrm{Cr}-\mathrm{Zr}$ alloy with different deformation structures remains at a sufficiently high level (Table 1), which exceeds the ductility of pure $\mathrm{Cu}$ subjected to ECAP [28]. The obtained results suggest an optimal route for commercial production of bulky $\mathrm{Cu}-\mathrm{Cr}-\mathrm{Zr}$ alloys. The feature of the strengthening mechanism in the $\mathrm{Cu}-\mathrm{Cr}-\mathrm{Zr}$ alloy enables high strength with excellent ductility and satisfactory electrical conductivity via one-pass ECAP processing. The production of a fully granular structure is unnecessary for achieving the optimal combination of these properties. Therefore, ECAP-Conform process under warm working conditions seems to be the most promising method for processing of advanced $\mathrm{Cu}-\mathrm{Cr}-\mathrm{Zr}$ semi-products with beneficial property combination.

\section{Conclusions}

The developed microstructures and mechanical properties of a $\mathrm{Cu}-0.87 \% \mathrm{Cr}-0.06 \% \mathrm{Zr}$ alloy subjected to multiple equal channel angular pressing up to $\varepsilon \sim 12$ at temperatures ranging from $473 \mathrm{~K}$ to $673 \mathrm{~K}$ were investigated. The main results can be summarized as follows.

1. The mean grain size gradually decreased from $\sim 4 \mu \mathrm{m}$ to $\sim 0.6 \mu \mathrm{m}$ as the number of ECAP passes increased from 1 to 8 , irrespective of processing temperature in the range of $473-$ $673 \mathrm{~K}$. In contrast, the dislocation density rapidly increased to $4 \times 10^{14} \mathrm{~m}^{-2}$ and $7 \times 10^{14} \mathrm{~m}^{-2}$ after one ECAP pass at $673 \mathrm{~K}$ and $473 \mathrm{~K}$, respectively, and remained essentially unchanged up to $\varepsilon \sim 8$. An insignificant decrease in dislocation density occurred upon further straining.

2. The grain refinement resulted from the progressive increase in the misorientations of the strain-induced low-angle boundaries during the multiple ECAP and could therefore be considered as a type of continuous dynamic recrystallization. The kinetics of ultrafine grain development hardly depended on the ECAP temperature. The fractions of ultrafine grains $\left(F_{\mathrm{UFG}}\right)$ with a size of $D \leq 2 \mu \mathrm{m}$ and high-angle boundaries $\left(F_{\mathrm{HAB}}\right)$ can be expressed by linear functions of total strain, $F_{\mathrm{UFG}}=0.07 \varepsilon$ and $F_{\mathrm{HAB}}=$ $0.2+0.04 \varepsilon$, in the strain range of $1 \leq \varepsilon \leq 12$.

3. The strengthening is attributed to the grain refinement and high dislocation densities evolved by large strain deformation. The deformation strengthening provided the major contribution to the overall strength increment. The role of the grain size strengthening is minor.

\section{Acknowledgments}

The financial support received from the Ministry of Education and Science, Russia, under Grant no. 14.575.21.0005 (ID no. 201414-576-0056-036) is gratefully acknowledged. The authors are grateful to the personnel of the Joint Research Centre, Belgorod State University, for their assistance with instrumental analysis.

\section{References}

[1] Q. Liu, X. Zhang, Y. Ge, J. Wang, J.-Z. Cui, Metall. Mater. Trans. A 37 (2006) 3233-3238.

[2] I.S. Batra, G.K. Dey, U.D. Kulkarni, S. Banerjee, J. Nucl. Mater. 299 (2001) $91-100$.

[3] H.T. Zhou, J.W. Zhong, X. Zhou, Z.K. Zhao, Q.B. Li, Mater. Sci. Eng. A 498 (2008) 225-230.

[4] Y. Amouyal, S.V. Divinski, Y. Estrin, E. Rabkin, Acta Mater. 55 (2007) 5968-5979.

[5] I. Shakhova, Z. Yanushkevich, I. Fedorova, A. Belyakov, R. Kaibyshev, Mater. Sci. Eng. A 606 (2014) 380-389.

[6] D.J. Edwards, B.N. Singh, S. Tahtinen, J. Nucl. Mater. 367-370 (2007) 904-909.

[7] C.Z. Xu, Q.J. Wang, M.S. Zheng, J.W. Zhu, J.D. Li, M.Q. Huang, Q.M. Jia, Z.Z. Du, Mater. Sci. Eng. A 459 (2007) 303-308.

[8] K. Valdes Leon, M.A. Munoz-Morris, D.G. Morris, Mater. Sci. Eng. A 536 (2012) 181-189.

[9] R.J. Hellmig, M. Janecek, B. Hadzima, O.V. Gendelman, M. Shapiro, X. Molodova, A. Springer, Y. Estrin, Mater. Trans. 49 (2008) 31-37.

[10] N. Takata, Y. Ohtake, K. Kita, K. Kitagawa, N. Tsuji, Scr. Mater. 60 (2009) 590-593.

[11] N. Takata, S.H. Lee, N. Tsuji, Mater. Lett. 63 (2009) 1757-1760.

[12] T. Akita, K. Kitagawa, K. Kita, M. Gotoh, Y. Hirose, N. Tsuji, J. Phys.: Conf. Ser. 240 (2010) 012119.

[13] K. Edalati, K. Imamura, T. Kiss, Z. Horita, Mater. Trans. 53 (2012) 123-127.

[14] Y. Estrin, A. Vinogradov, Acta Mater. 61 (2013) 782-817.

[15] G.V. Zel'dovich, N.Y. Frolova, I.V. Khomskaya, A.E. Kheifets, E.V. Shorokhov, P.A. Nasonov, Phys. Met. Metallogr. 115 (2014) 465-470.

[16] R.K. Islamgaliev, K.M. Nesterov, J. Bourgon, Y. Champion, R.Z. Valiev, J. Appl Phys. 115 (2014) 194301.

[17] R.K. Islamgaliev, K.M. Nesterov, Y. Champion, R.Z. Valiev, IOP Conf. Ser.: Mater. Sci. Eng. 63 (2014) 012118.

[18] K.X. Wei, W. Wei, F. Wang, Q.B. Dua, I.V. Alexandrov, J. Hu, Mater. Sci. Eng. A 528 (2011) 1478-1484.

[19] H. Feng, H. Jiang, D. Yan, L. Rong, Mater. Sci. Eng. A582 (2013) 219-224.

[20] A. Vinogradov, V. Patlan, Y. Suzuki, K. Kitagawa, I.V. Kopylov, Acta Mater. 50 (2002) 1639-1651.

[21] A. Vinogradov, T. Ishida, K. Kitagawa, V.I. Kopylov, Acta Mater. 53 (2005) 2181-2192.

[22] Ch. Xu, S. Schroeder, P.B. Berbon, T.G. Langdon, Acta Mater. 58 (2010) 1379-1386

[23] T.G. Langdon, Acta Mater. 61 (2013) 7035-7059.

[24] R.Z. Valiev, T.G. Langdon, Prog. Mater. Sci. 51 (2006) 881-981.

[25] M. Kato, Mater. Trans. 55 (2014) 19-24.

[26] A. Rohatgi, K.S. Vecchio, G.T. Gray, Metall. Mater. Trans. A32 (2001) 135-145.

[27] A.P. Zhilyaev, I. Shakhova, A. Belyakov, R. Kaibyshev, T.G. Langdon, Wear 305 (2013) 89-99.

[28] F. Dalla Torre, R. Lapovok, J. Sandlin, P.F. Thomson, C.H.J. Davies, E.V. Pereloma, Acta Mater. 52 (2004) 4819-4832.

[29] A. Belyakov, T. Sakai, H. Miura, K. Tsuzaki, Philos. Mag. A 81 (2001) 2629-2643.

[30] T. Sakai, A. Belyakov, R. Kaibyshev, H. Miura, J.J. Jonas, Prog. Mater. Sci. 60 (2014) 130-207.

[31] Y. Estrin, H.S. Kim, F.R.N. Nabarro, Acta Mater. 55 (2007) 6401-6407.

[32] O. Bouaziz, Y. Estrin, Y. Brechet, J.D. Embury, Scr. Mater. 63 (2010) 477-479. 
[33] J. Cizek, M. Janecek, O. Srba, R. Kuzel, Z. Barnovska, I. Prochazka, S. Dobatkin, Acta Mater. 59 (2011) 2322-2329.

[34] D.A. Hughes, N. Hansen, D.J. Bammann, Scr. Mater. 48 (2003) 147-153.

[35] A.A. Gazdera, W. Cao, Ch.H.J. Davies, E.V. Pereloma, Mater. Sci. Eng. A 497 (2008) 341-352.

[36] N. Kamikawa, X. Huang, N. Tsuji, N. Hansen, Acta Mater. 57 (2009) 4198-4208.

[37] S. Malopheyev, R. Kaibyshev, Mater. Sci. Eng. A620 (2014) 246-252.

[38] A. Mishra, B.K. Kad, F. Gregori, M.A. Meyers, Acta Mater. 55 (2007) 13-28.

[39] F.H. Dalla Torre, E.V. Pereloma, C.H.J. Davies, Acta Mater. 54 (2006) 1135-1146.

[40] C.F. Gu, L.S. Toth, M. Arzaghi, C.H.J. Davies, Scr. Mater. 64 (2011) 284-287.

[41] R. Kaibyshev, K. Shipilova, F. Musin, Y. Motohashi, Mater. Sci. Eng. A 396 (2005) $341-351$.

[42] M. Gazizov, S. Malopheyev, R. Kaibyshev, J. Mater. Sci. 50 (2015) 990-1005.

[43] G. Winther, X. Huang, A. Godfrey, N. Hansen, Acta Mater. 52 (2004) 4437-4446.

[44] F.J. Humphreys, P.B. Prangnell, J.R. Bowen, A. Gholinia, C. Harris, Philos. Trans. R. Soc. Lond. A 357 (1999) 1663-1681.

[45] F.J. Humphreys, M. Hatherly, Recrystallization and Related Annealing Phenomena, 2nd edn., Elsevier, Oxford, 2004.

[46] M. Mabuchi, K. Ameyama, H. Iwasaki, K. Higashi, Acta Mater. 47 (1999) 2047-2057.

[47] A. Belyakov, T. Sakai, H. Miura, R. Kaibyshev, Scr. Mater. 42 (2000) 319-325.

[48] I.J. Polmear, Light Alloys: From Traditional Alloys to Nanocrystals, 4th ed., Butterworth-Heinemann/Elsevier, UK, 2006.

[49] O.F. Higuera-Cobos, J.M. Cabrera, Mater. Sci. Eng. A 571 (2013) 103-114.

[50] R. Armstrong, I. Codd, R.M. Douthwaite, N.J. Petch, Philos. Mag. 7 (1962) $45-58$
[51] A.W. Thompson, M.I. Baskes, W.F. Flanagan, Acta Metall. 21 (1973) 1017-1028.

[52] N. Hansen, Scr. Mater. 51 (2004) 801-806.

[53] D.A. Hughes, N. Hansen, Acta Mater. 48 (2000) 2985-3004.

[54] X. Zhang, A. Godfrey, X. Huang, N. Hansen, Q. Liu, Acta Mater. 59 (2011) 3422-3430.

[55] R.Z Valiev, Mater. Trans. 55 (2014) 13-18.

[56] P. Kusakin, A. Belyakov, C. Haase, R. Kaibyshev, D.A. Molodov, Mater. Sci. Eng. A 617 (2014) 52-60.

[57] T.J. Harrell, T.D. Topping, H. Wen, T. Hu, J.M. Schoenung, E.J. Lavernia, Metall. Mater. Trans. A 45 (2014) 6329-6343.

[58] M.R. Ahmadi, E. Povoden-Karadeniz, L. Whitmore, M. Stockinger, A. Falahati, E. Kozeschnik, Mater. Sci. Eng. A 608 (2014) 114-122.

[59] F. Nembach, Phys. Status Solidi A 78 (1983) 571-581.

[60] M.R. Ahmadi, B. Sonderegger, E. Povoden-Karadeniz, A. Falahati, E. Kozeschnik, Mater. Sci. Eng. A 590 (2014) 262-266.

[61] I. Holzner, E. Kozeschnik, Mater. Sci. Eng. A 527 (2010) 3546-3551.

[62] M.R. Ahmadi, E. Povoden-Karadeniz, K.I. Oksuz, A. Falahati, E. Kozeschnik, Comput. Mater. Sci. 91 (2014) 173-186.

[63] J.C. Huang, A.J. Ardell, Acta Metall. 36 (1988) 2995-3006.

[64] R. Ueji, X. Huang, N. Hansen, N. Tsuji, Y. Minamino, Mater. Sci. Forum 426-432 (2003) 405-410.

[65] N. Hansen, X. Huang, R. Ueji, N. Tsuji, Mater. Sci. Eng. A 387-389 (2004) $191-194$.

[66] Z. Yanushkevich, A. Mogucheva, M. Tikhonova, A. Belyakov, R. Kaibyshev, Mater. Charact. 62 (2011) 432-437. 